\title{
General
}

\section{Role of Ketamine in the Treatment of Psychiatric Disorders}

\author{
Sahar Derakhshanian, MD', Maxine Zhou, MD', Alexander Rath, MD¹, Rachel Barlow, BS², Sarah Bertrand, BS², \\ Caroline DeGraw, BS², Christopher Lee, MD³, Jamal Hasoon, MD ${ }^{4}$ Alan D. Kaye, MD, PhD ${ }^{5}$ \\ 1 Department of Psychiatry, Louisiana State University Shreveport, LA, ${ }^{2}$ Louisiana State University Health Sciences Center Shreveport School of \\ Medicine, LA, ${ }^{3}$ Department of Internal Medicine, Creighton University School of Medicine-Phoenix Regional Campus, Phoenix, AZ, ${ }^{4}$ Department of \\ Anesthesiology, Critical Care, and Pain Medicine, Beth Israel Deaconess Medical Center, Harvard Medical School, Boston, MA, ${ }^{5}$ Department of \\ Anesthesiology, Louisiana State University Shreveport, LA \\ Keywords: mdd, intravenous, intranasal, spravato, ketamine, antidepressant, depression, trd \\ https://doi.org/10.52965/001c.25091
}

\section{Health Psychology Research}

Vol. 9, Issue 1, 2021

\section{Purpose of review}

This is a comprehensive review of the literature regarding the use of ketamine as a treatment for treatment-resistant depression (TRD). It covers the epidemiology, risk factors, pathophysiology, and current treatment modalities regarding Major Depressive Disorder (MDD) and TRD. It provides background on the mechanism of action of ketamine, its history, current approved and off-label indications in the field of psychiatry, and then provides an overview of the existing evidence for the use of ketamine in the treatment of TRD.

\section{Recent findings}

MDD is a mental illness that puts an enormous strain on the affected and a high socio-economic burden on society. The illness is complex and combines genetic, pathophysiologic, and environmental factors that combine to negatively affect neurotransmitter balance in the brain. Additional evidence suggests dysregulation of the hypothalamic-pituitary (HPA) axis, brain-derived neurotrophic factor (BDNF), vitamin D levels, and involvement of pro-inflammatory markers. Core symptoms include depressed mood or anhedonia, combined with neurovegetative symptoms such as sleep impairment, changes in appetite, feelings of worthlessness and guilt, and psychomotor retardation. Current first-line treatment options are antidepressants of the selective serotonin reuptake inhibitor (SSRI) and serotonin-norepinephrine reuptake inhibitor (SNRI) class. Failure to respond to two adequate trials of treatment meets the criteria for TRD. Esketamine (Spravato) is an NMDA-receptor antagonist with additional AMPA-receptor agonist properties, which the FDA approved in 2019 to treat adult TRD in conjunction with an oral antidepressant. It can be administered intranasally, providing a rapid response and proven effective and safe. Additional research suggests that oral ketamine might be effective for PTSD and anxiety disorders. Intravenous administration of ketamine has also shown benefits for acute suicidal ideation and depression and substance use to reduce relapse rates.

\section{Summary \\ TRD is associated with huge costs on individual and societal levels. Underlying disease processes are multifactorial and not well understood. Adjunctive therapies for TRD with proven benefits exist, but acutely depressed and suicidal patients often require prolonged inpatient stabilization. Intranasal esketamine is a new FDA-approved alternative with rapid benefit for TRD, which has also shown a rapid reduction in suicidal ideation while maintaining a favorable side-effect profile. Additional potential off-label uses for ketamine in psychiatric disorders have been studied, including PTSD, anxiety disorders, bipolar depression, and substance use disorders.}

\section{INTRODUCTION}

Depression is a persistent mood disorder that negatively impacts the social, vocational, and educational aspects of a person's life. While some patients experience reduction or elimination of symptoms after treatment, approximately $63 \%$ of patients do not receive an adequate response to a first-line antidepressant after 6-12 weeks of treatment. ${ }^{1} \mathrm{~Pa}$ tients with treatment-resistant depression (TRD) are defined as patients with depression who have not responded 
to consecutive treatments with at least two different antidepressants used for a sufficient length of time, at an adequate dose, and with an adequate affirmation of treatment adherence.

Depression is associated with a high economic burden and more significant healthcare costs. One study aimed to assess health care resource utilization (HCRU) and the burden and cost of treating patients with depression. This retrospective cohort study collected data from the Truven Health MarketScan Commercial and Medicare Supplemental Databases in the United States from October 1, 2008, through September 30, 2016. All patients were newly diagnosed with depression. Data indicated that in both commercially insured and Medicare-insured patients with depression, patients with TRD had more than $\$ 3000$ excess all-cause total healthcare payments in the 12 months following identification of TRD, and therefore, initiation of third-line treatment, compared to patients without TRD. ${ }^{1}$ Specifically, drivers of the excess economic burden associated with TRD included healthcare payments related to emergency department visits (0.29 vs. 0.24$)$, outpatient visits (18 vs. 13.4), and the number of prescriptions (30.0 vs. $24.0)$. This study concluded that improved and more effective management of patients with TRD, either before or following the progression of the disease, may help reduce the economic burden. ${ }^{1}$

A second study aimed to examine the humanistic and economic burden of TRD in five European countries, including France, Germany, Italy, Spain, and the United Kingdom, by comparing non-treatment resistant depression (nTRD) and general population respondents. Specifically, the sample for this retrospective observational study was taken from the 2017 National Health and Wellness Survey conducted in the aforementioned countries. Relative to the general population, nTRD and TRD respondents reported significant decreases in health-related quality of life, including lower adjusted mental and physical scores and increased relative risk for work and activity impairment. ${ }^{2}$ Furthermore, HCRU was significantly higher for TRD patients than nTRD, compared to the general population, particularly for healthcare professional visits. This study concluded that TRD patients had a significantly lower quality of life, less work productivity, more significant activity impairment, and increased healthcare resource utilization than nTRD and the general population. ${ }^{2}$

\section{HISTORY OF KETAMINE USE IN MEDICINE}

In the 1950s, scientists searching for an anesthetic agent with analgesic properties at Parke-Davis and Company's laboratory in Detroit, Michigan, discovered phencyclidine (PCP). This agent created potent analgesia in animals and led to subsequent studies of PCP as a human anesthetic under the trade name Sernyl. ${ }^{3}$ From $1957-1958$, PCP was administered as an anesthetic agent in humans undergoing surgery. This practice was later discontinued because some patients treated with PCP exhibited severe and prolonged post-surgical delirium. It became evident that PCP's utility as an anesthetic agent in humans was limited, and the search for drugs with fewer side effects continued. However, it was noted that PCP could have a role as an excellent drug model of schizophrenia. ${ }^{4}$

In the 1960 s, scientists synthesized a series of shortacting derivatives of PCP, including a compound known as ketamine. Ketamine provided potent analgesia. Compared to the problematic and prolonged effects on mental status seen with PCP, ketamine had a shorter duration of action and was less potent. ${ }^{3}$ In 1970 , ketamine was approved by the FDA for use in humans. In the 1980s, the discovery of the N-methyl-D-aspartate receptor (NMDAR) and its noncompetitive inhibition by ketamine prompted advances in mental functioning and memory pathophysiology. ${ }^{3}$ Current evidence suggests that the NMDAR antagonist, ketamine, produces a rapid and sustained antidepressant effect in treatment-resistant patients with MDD. ${ }^{4}$ Because of the quick onset of ketamine, it can provide rapid relief for depressive symptoms, unlike most antidepressants, which require several weeks to take effect. This rapid relief of symptoms makes ketamine a suitable potential candidate for various clinical situations, including preventing or shortening hospital stays, treating acute suicidal ideation, and facilitating medication crossovers.

\section{FDA-APPROVED INDICATIONS OF KETAMINE IN THE TREATMENT OF PSYCHIATRIC DISORDERS}

\section{ESKETAMINE (SPRAVATO) FOR TREATMENT-RESISTANT DEPRESSION (TRD) IN ADULTS}

Ketamine is a racemic mixture comprising equal parts of (R)-ketamine (or arketamine) and (S)-ketamine (or esketamine). Because (S)-ketamine has a higher affinity for NMDAR than (R)-ketamine, esketamine was chosen to be developed as an antidepressant treatment. ${ }^{4}$ In March of 2019, esketamine nasal spray, under the trade name Spravato, was approved by the U.S. Food and Drug Administration. Spravato nasal treatment combined with an antidepressant can produce a transient antidepressant response in patients diagnosed with TRD. In one trial, 227 adults with moderate to severe TRD (mean Montgomery-Asberg Depression Rating Scale [MADRS] score 37; scores range from 0-60, with higher scores indicating more severe symptoms of depression) were randomized to receive intranasal esketamine (flexible dosing; 56 or $84 \mathrm{mg}$ twice weekly) or placebo in addition to a new oral antidepressant. ${ }^{5}$ The average reduction in MADRS score at the end of the four-week trial was greater with esketamine than with placebo ( -19.8 vs. $-15.8 ; \mathrm{p}=0.01)$. Furthermore, most of the treatment efficacy of esketamine was apparent by 24 hours after the first dose. ${ }^{5}$

In a second trial, 176 adults in stable remission and 121 adults who were "stable responders" after 16 weeks of treatment with intranasal esketamine plus an oral antidepressant were randomized to either 1) continue taking the same regimen or 2) switch to intranasal placebo plus their oral antidepressant. Results indicated that relapse was less likely to occur in the group that received intranasal ketamine spray than the placebo in both the remission group ( $26.7 \%$ vs. $45.3 \%$; median time to relapse not reached with esketamine vs. 273 days with placebo) and responder group ( $25.8 \%$ vs. $57.6 \%$; median time to relapse 635 days with esketamine vs. 88 days with placebo). ${ }^{5}$ Combined, these two studies suggest the superiority of esketamine to placebo 
in lowering the MADRS score and preventing relapse. ${ }^{5}$ It should be noted that continuous use of esketamine was needed to maintain improvement, which may not be realistic for every patient due to financial cost and time constraints. Additionally, esketamine has the potential to cause severe cardiovascular and psychological adverse effects. These factors should be taken into consideration before prescribing this drug.

\section{DEPRESSIVE SYMPTOMS IN ADULTS WITH MAJOR DEPRESSIVE DISORDER (MDD) WITH ACUTE SUICIDAL IDEATION OR BEHAVIOR}

Evidence suggests that intravenous ketamine may help decrease suicidal ideation in some patients. Studies have observed a reduction in suicidal ideation, which lasts for several days following ketamine infusion. ${ }^{6}$ Particular studies have focused on vulnerable populations such as the military and cancer patients. In active-duty soldiers, psychiatric admission for suicidality may create logistical problems, including separation from the patient's support system, leading to potential administrative issues when it comes time to return to duty. In a small study of ten soldiers in the United States, one dose of intravenous ketamine $(0.2 \mathrm{mg} / \mathrm{kg})$ was found to decrease feelings of suicidality and hopelessness. ${ }^{7}$ Another study of 39 cancer patients indicated that intravenous ketamine $(0.5 \mathrm{mg} / \mathrm{kg})$ was efficacious in treating acute-onset depression and suicidal ideation. ${ }^{7}$

\section{OFF-LABEL INDICATIONS OF KETAMINE IN THE TREATMENT OF PSYCHIATRIC DISORDERS}

\section{KETAMINE INFUSION FOR DEPRESSION}

Intravenous infusion of ketamine was associated with higher remission rates and clinical response when compared to saline (placebo) or midazolam (active placebo). After 24 hours, depression scores were significantly reduced for patients treated with ketamine compared to placebotreated patients. While ketamine produced short-term psychotomimetic effects, there were no severe complications noted. ${ }^{6}$ Another trial concluded that depression scores were significantly improved in 127 cases of major depressive disorder compared to 112 MDD controls (SMD $=-0.91 ; 95 \% \mathrm{CI}$ $-1.19,-0.64 ; \mathrm{p}<0.01 ; \mathrm{I} 2=4.4 \%$ ) with ketamine use. ${ }^{8}$

\section{PTSD, ANXIETY, AND BIPOLAR DEPRESSION}

A retrospective review conducted in Australia studied longterm oral ketamine use for post-traumatic stress disorder (PTSD) and treatment-resistant depression (TRD). Results indicated that hospital admissions were reduced by $65 \%$, and inpatient hospital days were reduced by $70 \%$ following oral ketamine treatment. No evidence of tolerance-building or serious adverse effects were noted after the use of ketamine. ${ }^{9}$ Anxiety disorders and PTSD both utilize pathological avoidance behavior. Ketamine facilitated avoidance of behavior in a subset of Wistar Kyoto (WKY) rats, with effects lasting three weeks, suggesting that ketamine may help treat anxiety disorders by reducing avoidance behaviors and enhancing hippocampal synaptic plasticity. ${ }^{10}$
In a double-blind study of 12 patients with treatment-resistant generalized anxiety disorder and social anxiety disorders, improvements in anxiety ratings occurred within an hour of ketamine dosing and lasted up to one week. ${ }^{11}$ Another study analyzed the effect of NMDAR antagonists ketamine and dizocilpine/MK-801 on conflict-evoked fear behaviors in mice exposed to an elevated T-maze. In this trial, ketamine did not affect the behavioral tasks performed in the elevated T-maze acutely or 24 hours later. MK-801 impaired inhibition avoidance in the maze only at 45 minutes post-injection, indicating a rapid but not sustained anxiolytic-like effect. Therefore, this study concluded that ketamine might have mixed effects on anxiety tests. ${ }^{12}$

\section{COCAINE USE DISORDER, OPIATE USE DISORDER, ALCOHOL USE DISORDER}

One study of 55 cocaine-dependent patients found that a single infusion of ketamine, combined with a mindfulness behavior modification program, decreased the risk of relapse and encouraged abstinence compared to a single infusion of midazolam, the control group. At the end of the four-week trial, $48.2 \%$ of the ketamine group were abstinent compared to the $10.7 \%$ of the midazolam group. ${ }^{13}$ Another study comparing the effects of ketamine and midazolam determined that ketamine leads to significantly more significant acute mystical-type effects (by Hood Mysticism Scale: HMS), dissociation (by Clinician-Administered Dissociative States Scale: CADSS), and near-death experience phenomena (by the Near-Death Experience Scale: NDES). Notably, the HMS score was found to mediate the effect on decreased cocaine use and craving. ${ }^{13}$

A randomized controlled trial of 70 heroin-dependent patients analyzed the effects of different ketamine doses on abstinence rates over time. Abstinence rates at one month approached $85 \%$ in the $2 \mathrm{mg} / \mathrm{kg}$ group compared to $55 \%$ in the $0.2 \mathrm{mg} / \mathrm{kg}$ group ( $<<0.01$ ), and were $24 \%$ after one year in the $2 \mathrm{mg} / \mathrm{kg}$ group compared to $6 \%$ in the $0.2 \mathrm{mg} / \mathrm{kg}$ group ( $\mathrm{p}<0.05) .{ }^{14}$ In addition to the comparison of dosage, this study considered the effects of repeated sessions of ketamine-assisted psychotherapy. Participants were randomized to either one or three sessions of ketamine administration (2mg/kg I.M., given at 1-month intervals) in the study. They found that $50 \%$ of subjects receiving multiple ketamine treatments were abstinent at 1 -year follow-up, compared to $22 \%$ of single-session treatments $(\mathrm{p}<0.05) .{ }^{14}$

Ketamine may disrupt the maladaptive reward memory (MRM) system, which is theorized in alcohol use disorders. A study showed that MRM retrieval combined with ketamine effectively reduced the reinforcing effects of alcohol and long-term drinking level compared to retrieval alone. ${ }^{15}$ A family history of alcohol use disorder is a positive predictor of ketamine's antidepressant effect, and strength of association increases over time. This study concluded that ketamine's extended antidepressant durability in family history-positive TRD should be considered to design and analyze ketamine depression trials. ${ }^{16}$ 


\section{MAJOR DEPRESSIVE DISORDER EPIDEMIOLOGY, PATHOPHYSIOLOGY, RISK FACTORS, AND PRESENTATION}

Major depressive disorder (MDD) constitutes one of the largest public health dilemmas in the United States. The National Institute of Mental Health reported that 16.2 million people (6.7\% of the U.S. adult population) experienced a depressive episode in 2016. ${ }^{17}$ Patients with MDD who receive adequate treatment are not guaranteed full recovery or remission- only $30 \%$ of patients with MDD receiving adequate care experience full recovery or remission, and of the remaining $70 \%$, half will not respond to treatment. ${ }^{17}$ Those who experience persistent MDD following two rounds of failed adequate trials of antidepressant therapy are subsequently categorized as individuals with TRD. ${ }^{17}$ Patients with TRD are twice as likely to be hospitalized in comparison to depressed patients who are not treatment-resistant. ${ }^{17}$

Mortality from external causes, such as suicides and accidents, was higher in TRD patients when compared to other depressed patients, with a hazard ratio of $1.97 .{ }^{18}$ Additionally, patients with TRD have increased all-cause mortality compared to other depressed patients, primarily due to external causes of death. Young and physically healthy patients have the highest relative mortality from TRD. ${ }^{18}$ The prevalence of MDD in 18- through 29-year-old patients is three times higher than the prevalence in patients over 60 years old. Prevalence in females is 1.5 to 3 , higher than in males starting in early adolescence. ${ }^{19}$ Evaluating the epidemiology of MDD is essential for understanding the applications and efficacy of ketamine in the treatment of refractory MDD. Evaluating the prevalence of MDD in specific U.S. demographic groups (e.g., age, ethnic, racial groups) is necessary to address disparities in disadvantaged groups. Treatment of MDD with comorbidities may differ; therefore, obtaining data on prevalence, mortality, and morbidity of MDD with concurrent disorders is also necessary.

Though not completely understood, meta-analyses support the possible involvement of multiple pathophysiological mechanisms in MDD and TRD. These mechanisms involve inflammation, the hypothalamic-pituitary (HPA) axis, brain-derived neurotrophic factor (BDNF), and vitamin D. ${ }^{20}$ Upregulation of inflammation followed by a decrease in the production of monoamines, like serotonin, and an increase of brain-toxic tryptophan catabolites may contribute to MDD. ${ }^{20}$ Studies have shown that depressed subjects showed a significant increase in IL-6, IL-8, and acute phase C-reactive protein, all of which are pro-inflammatory cytokines. Another possible pathophysiological mechanism in MDD that has been studied extensively is hyperactivity of the HPA axis. ${ }^{20}$ The HPA axis controls the secretion of glucocorticoids and corticotropin-releasing factor (CRF), both of which are critical elements of the stress response. Mutating HPA genes is a technique employed to create genetic models of depression. Overexpression of the CRF1 receptor in mice is associated with enhanced depressive life features. ${ }^{21}$ Hyperactivity of the HPA axis may be caused by malfunctioning glucocorticoid receptors impairing the negative feedback circuit of the HPA axis. This dysfunction may be associated with MDD progression. ${ }^{21}$ A third possible pathophysiological mechanism of MDD involves low levels of BDNF. Low levels of BDNF are seen as a sign of reduced neurotrophic growth, contributing to MDD. ${ }^{20}$ Rodents from the depressive rat line exhibit depressive-like behaviors correlated with low levels of BDNF in specific regions of the brain. ${ }^{22}$ Recent meta-analyses have supported the idea that patients with MDD have lower BDNF levels than control patients. ${ }^{20}$ Finally, recent meta-analyses show that low vitamin D levels may serve as a fourth pathophysiologic mechanism of MDD. ${ }^{20}$ By reducing neurotoxic calcium levels in the brain, vitamin D may provide neuroprotective effects. ${ }^{20}$ Though little is known about how TRD differs from treatment-responsive depression, the heterogeneity of MDD and its possible pathophysiological mechanisms may contribute to the lack of a stratification system for distinct depressive subtypes. ${ }^{21}$ MDD and TRD have a plethora of possible symptomatic combinations that meet DSM-V criteria. The 681 possible symptom combinations reflect the variety of possible presentations of MDD. ${ }^{21}$ Such variability in pathophysiology and etiology reflects variability in treatment response to drugs such as ketamine. Further research regarding differences in medication regimen responses, brain circuitry and function, and early life stressors are necessary to determine reliable treatments for MDD.

There are several familial, individual, and genetic risk factors for major depressive disorder. ${ }^{23}$ Risk and prognostic factors for MDD are grouped into categories by the DSMV: temperamental, environmental, genetic, and physiological. Environmental factors such as adverse childhood experiences and stressful life events are common triggers for MDD. ${ }^{19}$ Genetic and physiological factors also play a role in the risk of MDD. First-degree family members of patients with MDD have two to four times higher risk of developing MDD, with higher relative risk in early-onset forms. High levels of neuroticism also tend to render people more likely to develop MDD. ${ }^{19}$ Heritability is estimated to be between 40-60\%. ${ }^{19}$ Other risk factors include symptom severity, suicidal risk, a higher number of lifetime depressive episodes, comorbidities, and anxiety disorders. ${ }^{24}$ Predictors of earlier onset and recurrent courses of major depressive disorder include parental psychiatric status, poor academic functioning, poor quality parent-child relationships, and childhood maltreatment by age 11.23

The common diagnostic features of depressive disorders are a sad, empty, irritable mood accompanied by cognitive and somatic changes that cause a significant change in the patient's ability to function. Depressive disorders differ in etiology, duration, and timing of the illness, but the essential feature of MDD is two weeks of depressed mood or anhedonia. ${ }^{19}$ A "depressed mood" may be described by the patient as a sad, hopeless, or discouraged feeling. Other symptoms of MDD may include an increase or reduction in appetite, sleep disturbances, fatigue, suicidal ideation, or suicidal attempts. ${ }^{19}$ Changes in appetite due to MDD may result in symptomatic weight gain or loss. Symptomatic insomnia often takes the form of middle insomnia, which is waking in the middle of the night and not being able to get back to sleep. ${ }^{19}$ Depression has been observed in children as young as three years old, although children of such young age are unlikely to verbalize feelings or meet DSM criteria 
for MDD. ${ }^{25}$

\section{CURRENT APPROACHES TO TREATMENT- RESISTANT DEPRESSION}

Diagnosis of treatment-resistant depression requires a "minimum of two prior treatment failures and confirmation of prior adequate dose and duration". ${ }^{17}$ First-line treatments for mild, moderate, and severe depression include SSRIs and SNRIs no matter the clinical severity. ${ }^{26}$ In cases of mild MDD, psychotherapy can be used alone, while psychotherapy in combination with pharmacologic therapy is recommended in cases of moderate to severe MDD. ${ }^{26}$ The purpose of psychotherapy in MDD is to provide patients with psychological support, inform patients about their disease process and psychopathology, increase therapeutic alliance, increase pharmacotherapy adherence, improve quality of life, and manage psychiatric comorbidities. ${ }^{26}$

Second-line treatments include tricyclic antidepressants (TCAs), $\alpha 2$-antagonists, and agomelatine. However, these second-line treatments are primarily first-generation antidepressants. While these agents may have therapeutic effects, they are associated with various side effects that make second-generation antidepressants a more preferential treatment. $^{27}$ Side effect burdens, previous treatment responses, and previous medication histories are all important factors when deciding upon appropriate therapies for TRD. ${ }^{26}$ TRD is complex and reflects various depressive subtypes, medical and psychiatric comorbidities. ${ }^{17}$ Developers of guidelines are limited by the definition of TRD and the various array of findings in diverse patient populations. ${ }^{17}$ In defining "resistance," psychiatric texts refer to residual depressive symptoms following adequate treatment courses and loss of treatment effectiveness as time passes. ${ }^{21}$ There are limited treatment options for patients with increasing depressive resistance. Standard treatment options for TRD include switching antidepressant classes, medicine regimen augmentation, and electroconvulsive therapy; however, evidence on the effectiveness of these treatment plans is limited. $^{28}$ Augmenting agents include but are not limited to anticonvulsants, lithium, and atypical antipsychotics. ${ }^{28}$ Another adjunctive therapy that may be useful in Stage 1 TRD is vortioxetine. ${ }^{29}$

There are three main types of antidepressant switch strategies: concurrent switch, overlapping switch, and sequential switch. The concurrent switch involves changing medication dosage and gradual upward titration of a new medication during gradual downward titration of the original medication. ${ }^{26}$ The overlapping switch mechanism involves dose changes for one medicine while keeping the original medication in its initial dose until the second medication reaches the optimal dosage. Finally, the sequential switch mechanism involves titrating the current medication dosage downward until the interruption of therapy when a new medication is introduced. ${ }^{26}$ The recommended switch guideline is that of the concurrent switch unless the patient receives a monoamine oxidase inhibitor therapy. These switch mechanisms are indicated when the patient has no response to initial treatment or poor tolerance to initial treatment. ${ }^{26}$
An example of combination drug therapy is adding lithium or quetiapine to an ongoing anti-depressive therapy to compound its efficacy. ${ }^{26}$ Another example of combination therapy is the addition of thyroid hormone to SNRI, TCA, SSRI, or $\alpha 2$-antagonists therapy. ${ }^{26}$ A review of twelve randomized controlled trials considered the clinical effectiveness of SSRIs in combination with lithium to that of SSRIs in combination with placebo. The results indicated a trend in favor of lithium augmentation for a therapeutic response. ${ }^{28}$ Augmentation of SSRI therapy with lithium is likely beneficial in people with TRD. ${ }^{28}$ Lithium, along with electroconvulsive therapy (ECT), is also thought to be beneficial in the prevention of recurrence of MDD. ${ }^{26} \mathrm{ECT}$ is not recommended as a first-line treatment for MDD, no matter the clinical severity. ECT should not be considered as a therapy until the failure of three adequately conducted treatments. ${ }^{26}$ Cannabidiol has also been researched as a possible therapeutic treatment for TRD. Cannabidiol compounds may induce a reversal effect of chronic unpredictable mild stress on corticosterone concentrations, indicating a possible antidepressant-like effect. ${ }^{30}$

Many patients suffering from TRD undergo a "trial and error" approach to their treatment because of the lack of guidelines for optimal management. Additionally, treatment resistance is common in MDD patients over time despite a large variety of treatment options. ${ }^{21,26}$ The rapid antidepressant effects of ketamine pose a stark contrast with the delayed effects of the currently approved treatment regimens for TRD. ${ }^{31}$ This proves to be an important feature when considering, for example, patients with suicidal ideations in which a lag or delay in onset of antidepressant effect can lead to increased risk for suicidal behaviors. ${ }^{31}$ Suicidality is just one symptom in the criteria for MDD diagnosis; not only has ketamine been shown to induce rapid resolution of suicidal ideation in MDD patients, but it is associated with the rapid reduction of anhedonia. ${ }^{18,31}$ Clinical trials surrounding monotherapies, adjunct therapy strategies, psychotherapy, and combinations of all of these therapy options are needed to develop methods and measures to assess behavioral factors associated with TRD. ${ }^{26}$

\section{SPRAVATO: DRUG INFORMATION}

Spravato (esketamine) is the s-enantiomer of ketamine available as a nasal spray. ${ }^{5}$ Spravato was approved by the U.S. Food and Drug Administration in conjunction with oral antidepressant therapy to treat adult TRD and is the first FDA-approved form of esketamine. ${ }^{32}$ The active ingredient of Spravato is esketamine hydrochloride, and inactive ingredients include citric acid monohydrate, edetate disodium, sodium hydroxide, and water. The active ingredient, esketamine hydrochloride, is a non-competitive N-methyl D-aspartate (NMDA) receptor antagonist. The drug is available through a restricted distribution system due to its potential for abuse and its potential adverse effects, as discussed below. ${ }^{32}$

Spravato should be administered intranasally under the guidance of a healthcare provider. Spravato is dosed at 14 $\mathrm{mg}$ of esketamine per spray, requiring administration of 
2 sprays per device. Blood pressure should be measured before and after administration. Of note, Spravato is contraindicated in patients with aneurysmal vascular disease, intracerebral hemorrhage, or hypersensitivity to any of the inactive or active ingredients. The therapeutic benefit of Spravato should be evaluated following a 4-week course of therapy to determine the need for continued treatment. ${ }^{5}$

Spravato poses a risk for sedation and dissociation following administration; therefore, patients should be monitored for a minimum of two hours following administration of the drug. The potential for misuse or abuse of the drug should be considered before the prescription of Spravato in at-risk patients. Spravato is not currently approved for use in pediatric patients. All patients should be monitored for the emergence of increased suicidal thoughts and behavior while on antidepressant therapy. An increase in blood pressure, cognitive impairment, impaired ability to drive and operate machinery, and embryo-fetal toxicity may be precipitated by Spravato use; thus, it is important for close monitoring. However, the most common adverse reactions to the use of Spravato are dissociation, dizziness, nausea, vomiting, sedation, vertigo, hypoesthesia, anxiety, lethargy, increased blood pressure, and increased emotional states. ${ }^{5}$

\section{MECHANISM OF ACTION}

Clinical trials regarding the use of ketamine in TRD have provided evidence that a single, sub-anesthetic dose of ketamine induces rapid and sustained antidepressant actions in patients with MDD. ${ }^{31}$ Several hypotheses exist for ketamine's mechanism of action and its role as an antidepressant in placebo-controlled trials. Ketamine, an NMDAR antagonist, has been shown to provide antidepressant effects within hours and sustained results for up to seven days. ${ }^{31}$ Direct synaptic or extra-synaptic NMDAR inhibition, selective inhibition of NMDARs on GABAergic interneurons, and $\alpha$ amino-3-hydroxy-5-methyl-4-isoxazole-propionic acid receptor (AMPAR) activation are all proposed mechanisms of ketamine's rapid action. ${ }^{31}$ Additionally, the antidepressant actions of the drug may be related to downstream mechanisms that regulate synaptic plasticity, including effects on BDNF, eukaryotic elongation factor 2 (eEF2), mechanistic target of rapamycin (mTOR), and glycogen synthase kinase-2 (GSK-3). ${ }^{31}$

NMDARs are heterotetrameric, glutamatergic, ligandgated ion channel receptors with seven subunits. Activation of the receptor requires concurrent binding of the GluN2 and GluN1 subunits and voltage-dependent repulsion of an $\mathrm{Mg} 2+$ blockage at the ion channel pore. ${ }^{31}$ Removal of the magnesium block results in calcium influx. Direct inhibition of the NMDAR may represent a target for faster-acting antidepressant actions compared to the classical antidepressants that indicate adaptive, slower changes to the NMDAR receptor. ${ }^{31}$ AMPAR receptors are involved in the transduction of fast synaptic neurotransmission in the brain and the target of many signaling pathways that regulate synaptic plasticity. AMPAR and NMDAR activation are essential for synaptic plasticity and are considered important in the role of ketamine's antidepressant activity. ${ }^{31}$ While the antagonism of the NMDAR predominates as ketamine's proposed mechanism of action, the true mechanistic explanation for the drug's rapid onset anti-depressive effects is unknown. Several novel drug-discovery targets are currently being researched in medicinal chemistry, pharmacologic research, and animal models. ${ }^{33}$

\section{PHARMACOKINETICS/PHARMACODYNAMICS}

As discussed, ketamine has shown antidepressant effects in numerous studies; however, the exact mechanism to this is still not well understood. It is known that ketamine is an NMDAR antagonist. Still, when researchers attempted to replicate the antidepressant effects of ketamine using an alternative NDMAR antagonist, there was little success. ${ }^{34}$ Additional clinical research suggests that the efficacy of ketamine as an antidepressant is due to its relationship in the activation of the opioid receptor system. ${ }^{35}$ There is data that indicates that ketamine may increase the release of glutamate. Additionally, decreased effects of ketamine as an anesthetic have been observed in the context of lamotrigine (a medication that decreases the release of glutamate) overdose, suggesting that ketamine may have undesirable drug interactions with drugs that have glutaminergic action. However, the connection between these additional interactions and antidepressant effects remains unknown. ${ }^{36}$ Additionally, benzodiazepines may reduce the efficacy of ketamine as an antidepressant. ${ }^{37}$ The exact mechanism of this finding is unknown but is thought to be due to the non-specific central depressant effect of benzodiazepines. Other potential interactions to consider with ketamine affect the CYP2B6, CYP2C9, and CYP3A4 enzymes. In vitro studies have indicated these enzymes to have the highest metabolic activity for both enantiomers of ketamine. 38,39

Commercially available ketamine contains a 1:1 racemic mixture of both enantiomers. Studies indicate a difference between the pharmacodynamics, pharmacokinetics, side effects, and efficacy of these two. ${ }^{40-42}$ For instance, in a clinical study looking at the difference between the two as anesthetics, the (S) enantiomer showed fewer psychotic emergent reactions and less agitated behavior. ${ }^{43}$ There have been many studies that have demonstrated the efficacy of the (S)-ketamine as a treatment of depression. Still, even with these known distinctions in characteristics, the (R) enantiomer has also shown potential in animal studies to be an antidepressant option. ${ }^{44-47}$ To date, there have still not been any clinical studies directly comparing the utility of the $(\mathrm{R})$ enantiomer compared to the $(\mathrm{S})$ or the racemic mixture as effective as an antidepressant. ${ }^{48}$

\section{CLINICAL STUDIES: SAFETY AND EFFICACY}

In one randomized, double-blind, active-controlled study, the use of esketamine nasal spray in adults $(\mathrm{N}=346)$ with moderate-to-severe depression who have previously had no response to at least two other antidepressant medications was considered. The participants were treated twice a week either with esketamine nasal spray (esketamine [56 or 84 $\mathrm{mg}]$ ) in addition to an open-label, oral antidepressant or a placebo with the oral antidepressant. ${ }^{49}$ Although results 
were not statistically significant for the primary endpoint (change from baseline to day 28 in the MADRS total score), the treatment effect for the esketamine combined with antidepressant groups has shown to demonstrate meaningful clinical efficacy in improving symptoms. Additionally, there were adverse effects seen similarly in all three groups, so it was determined that there was no significant difference in safety and tolerability, and no new safety concerns were identified. The study concludes that esketamine shows potential in being a safe and effective rapid-acting antidepressant in treatment-resistant depression. ${ }^{49}$

A different study also compared the efficacy of different doses of intranasal esketamine to a placebo for the treatment of TRD. ${ }^{50} \mathrm{~A}$ randomized group of adults diagnosed with TRD and failed a trial of two other antidepressants were randomized into groups $(3: 1: 1: 1)$ receiving intranasal placebo or esketamine $(28,56$, or $84 \mathrm{mg})$ twice weekly. 50 Those in the placebo group who showed severe symptoms were randomized a second time $(1: 1: 1: 1)$ at the end of one week. Results were statistically significant and showed improvement in the mean MADRS total score in all esketamine dose groups (least-squares mean difference ranging from -5.0 to -10.5 in period 1 and from -3.1 to -6.9 in period 2 ). In the participants who received the same dosing for both phases of the study, there was a more significant portion of responders (individuals who had $\geqslant 50 \%$ improvement from baseline in MADRS total score) in the esketamine groups (28 mg: 38\% [3 of 8], $56 \mathrm{mg}: 36 \%$ [4 of 11], $84 \mathrm{mg}: 50 \%$ [5 of 10], and placebo: $10 \%$ [1 of 10]). Three common adverse events reported included dizziness, headache, and dissociative symptoms, which occurred more frequently in esketamine groups than in the placebo group. A dose-dependent relationship was seen with symptoms of dizziness. Dissociative effects were lessened on repeat dosing without affecting overall clinical efficacy. Overall, esketamine showed no concerning safety issues with effectiveness in treating TRD. 50

A separate randomized trial evaluating the efficacy of IV administered esketamine showed promising changes in the MADRS score compared to a placebo. Thirty patients who had been diagnosed with TRD were randomized (1:1:1) to receive either an IV infusion over 40 minutes $(.20 \mathrm{mg} / \mathrm{kg}$ or $.40 \mathrm{mg} / \mathrm{kg}$ esketamine) or a placebo. ${ }^{51}$ The MADRS total score was analyzed at the end of day one and reassessed at the end of day two. The improvement in patients after 24 hours was mainly in those receiving the esketamine treatment (score for the esketamine $.20 \mathrm{mg} / \mathrm{kg}$ and $.40 \mathrm{mg} / \mathrm{kg}$ dose groups were -16.8 (3.00) and -16.9 (2.61) respectively) compared to the placebo treatment(one-sided with $.10 \mathrm{sig}$ nificance level, $p=.001$ for both esketamine groups). Esketamine effects were rapid and showed to be persistent on revaluation on day 35 . Similar side effects were seen in all groups, but more often in the higher esketamine dosage $(.40 \mathrm{mg} / \mathrm{kg})$ group. The most commonly experienced side effects were nausea and headache, along with dissociation seen in the esketamine $.40 \mathrm{mg} / \mathrm{kg}$ group. The dissociative events were found to peak at 40 minutes after infusion, and however, symptoms subsequently resolved within 4 hours. Although the sample size was limited, the small study showed statistically significant data that IV esketamine has the potential to treat TRD. ${ }^{51}$
In another randomized, parallel-group, triple-masked clinical trial, the utility of ketamine on patients who were in the midst of a major depressive episode with no active suicidal ideation was analyzed. The 38 participants were randomized in groups to receive either one intravenous ketamine infusion over 40 minutes $(0.1,0.2,0.3,0.4$ or $0.5 \mathrm{mg} /$ $\mathrm{kg}$ ) or placebo. In addition to utilizing the Hamilton Depression Rating Scale to track the patient's depression score, this study also examined the ventromedial prefrontal cortex Glx (glutamine or glutamate) and GABA levels after each infusion. ${ }^{52}$ The results showed a positive relationship between the levels of ketamine in the blood and clinical improvement as reported by the patient $\left(t_{36}=12.08 ; P<.001\right.$; slope estimate, 10.5 [95\% CI, 175.2 to 245.9]). However, when the ketamine dose and Glx response were analyzed together, the ketamine dose was no longer associated with antidepressant effect, suggesting that the Glx response mediates this relationship. The psychomimetic adverse effects of ketamine were analyzed using the Brief Psychiatric Rating Scale (BPRS). BPRS score was found not to correlate to the level of ketamine or the patient's clinical outcome. This study explored ketamine's potential as an antidepressant while providing insight into a relationship between ketamine, Glx, and clinical response. ${ }^{52}$

Ketamine treatment was also researched to evaluate for effectiveness in reducing suicidal ideation. 71 patients who endorsed suicidal ideation were recruited and subsequently randomized into three different groups to either receive $0.5 \mathrm{mg} / \mathrm{kg}$ ketamine, $0.2 \mathrm{mg} / \mathrm{kg}$ ketamine, or normal saline infusion acting as the placebo. ${ }^{53}$ Both the HAMD and MADRS scores were implemented and used every few days up to two weeks. The patients who have TRD with baseline suicidal symptoms (item 3 of theHAMD $\geqslant 1[n=67]$ or item 10 of the MADRS $\geqslant 2[n=58]$ ) who were in the ketamine infusion groups showed a statistically significant reduction in suicidal symptoms ( $p=0.002$ ). The study found the $0.5 \mathrm{mg} / \mathrm{kg}$ ketamine infusion was more effective in treating those who endorsed severe suicidal symptoms, based on their baseline scores. This clinical study did not report on the adverse effects experienced by participants, but it did demonstrate that ketamine has the potential to be used to rapidly reduce suicidal symptoms. ${ }^{53}$

An extension of the previous study examined the role of pro-inflammatory cytokines in TRD. The same methodology was used for this study, with the exception that only MADRS was used. In addition to getting the participants' MADRS total score, their levels of pro-inflammatory cytokines were also obtained. The pro-inflammatory cytokines that were studied include CRP, IL-6, and TNF- $\alpha$. These levels were all obtained before initiating test infusions, then $40 \mathrm{~min}$ post-infusion, $240 \mathrm{~min}$ post-infusion, and on Day 3 and Day 7 of the study. ${ }^{54}$ There was no significance in the change of CRP levels, but the levels of IL-6 $(p=0.002)$ and TNF- $\alpha(p=0.001)$ changed significantly over time, being lower 40-240 min post-infusion. TNF- $\alpha$ changes were positively correlated with changes in the MADRS score. This study did not talk about adverse effects experienced or safety of ketamine, but it is one of the first clinical studies relating cytokines to the severity of TRD and the use of ketamine as a rapid treatment. ${ }^{54}$

A randomized, double-blind study looked at the efficacy 
of ketamine in a long-term outpatient setting, evaluating the impact of chronic ketamine use to treat TRD. Twentysix patients who suffered from severe MDD and chronic suicidal symptoms were randomized to receive six infusions of ketamine $(0.5 \mathrm{mg} / \mathrm{kg}$ over 45 minutes $)$ or a saline placebo over three weeks. The efficacy of ketamine was measured using the HDRS score, and the severity of suicidal ideations was measured by evaluating with the Columbia-Suicide Severity Rating Scale (C-SSRS) scores. ${ }^{55}$ After the completion of infusions, $42 \%$ of patients who received ketamine treatment met the criteria for the absence of suicidal ideations compared to $25 \%$ in the placebo group. There was no statistically significant difference between the use of ketamine on long-term suicidal ideation. After the final infusion, $25 \%$ of patients in the ketamine group reported an antidepressant response compared to $33 \%$ in the placebo group. There was no significant difference between the proportion of responders or remitters in the ketamine and placebo group at the three months follow-up. This suggests that although doses of $0.5 \mathrm{mg} / \mathrm{kg}$ may be effective in the short-term treatment of symptoms, it may not be sufficient in the long term for chronically ill patients. ${ }^{55}$

An additional randomized double-blind was done to study the efficacy of nasally administered esketamine as an adjunct to antidepressant therapy for actively suicidal patients. Patients $(\mathrm{N}=68)$ were randomly assigned to a group to either receive esketamine (84 $\mathrm{mg}$ ) twice a week for 4 weeks or a placebo spray. The drug's efficacy was judged based on a change in the baseline MADRS total score after 4 hours, 24 hours, and then again at 25 days. Patients were also being assessed clinically for their overall suicide risk. ${ }^{56}$ The esketamine groups showed a significant improvement in MADRS score compared to the placebo group until the measurement at day 25 (least-square mean difference $=-4.5$, $\mathrm{SE}=3.14$; effect size=0.35). However, the clinical judgment of suicide risk did not show statistical significance. The most common adverse effects were seen in many of the other clinical trials, including nausea, dizziness, dissociation, and headache. These findings show that intranasal ketamine has utility in rapid improvement of depressive and suicidal symptoms, but data did not support any long-term improvement. 56

Much research suggests that there may be a difference in efficacy of the different enantiomers and the racemic ketamine mixtures, but this has only been researched in animal models. ${ }^{57}$ The clinical trials that have been done to examine this difference have mainly been investigating the anesthetic capabilities of ketamine. ${ }^{58}$ There has been a protocol published planning to explore the difference in enantiomers in patients with TRD. In this planned study, patients will be randomized in a double-blind study and receive an infusion of either esketamine or ketamine at $0.25 \mathrm{mg} / \mathrm{kg}$ or $0.5 \mathrm{mg} / \mathrm{kg}$, respectively. ${ }^{59}$ This could potentially assist in finding the most efficacious version of a drug that has already been shown in many other clinical trials to be a capable and relatively safe option for TRD.

\section{CONCLUSION}

Typical treatment for TRD includes pharmacotherapy, psychotherapy, and stimulation therapies. Currently, oral an- tidepressants are the mainstay form of pharmacotherapy. There is an overwhelming need to address the obstacles in treating TRD due to the delayed treatment response with oral antidepressants and the poor response rate. New modalities and drugs can be explored to alleviate the severity of symptoms. While ketamine was initially approved as a general anesthetic, it has been repurposed to treat depressive disorders, suicidal ideation, and other off-label uses such as substance-use disorders and anxiety disorders.

Following FDA approval of intranasal (S)-ketamine used in conjunction with an oral antidepressant, other potential routes of administration, including intravenous and oral, are currently being researched and explored. An advantage of IV administration is the rapid antidepressant response observed. The effects of ketamine in these patients can be observed within 24 hours of the initial dose and last 4-7 days after one intravenous infusion. ${ }^{60} \mathrm{~A}$ disadvantage of IV ketamine administration is its high cost, inconvenience, and impractical nature for many patients. These disadvantages associated with intravenous administration led to an analysis of the efficacy of oral esketamine as an adjunct to oral antidepressant medication. ${ }^{61}$ Oral administration can improve compliance and ease of use compared to the intravenous or intranasal route.

Ketamine has been associated with the potential for abuse due to its ability to cause psychotropic side effects. Some of these effects include hallucinations, false beliefs, and impairments in judgment. ${ }^{62}$ Other side effects of ketamine administration in doses required for anti-depressive effects include headache, dizziness, dissociation, increased blood pressure and heart rate, blurred vision, nausea, drowsiness, and anxiety. ${ }^{63}$ The costs and benefits must be considered before treatment with ketamine begins.

Submitted: June 01, 2021 EST, Accepted: June 17, 2021 EST 
Table 1. Clinical safety and efficacy

\begin{tabular}{|c|c|c|c|}
\hline $\begin{array}{l}\text { Author } \\
\text { (Year) }\end{array}$ & Groups Studied and Intervention & Results and Findings & Conclusion \\
\hline $\begin{array}{l}\text { Fedgchin, } \\
\text { et al. } \\
\text { (2019) }\end{array}$ & $\begin{array}{l}\text { Phase 3, double-blind, multicenter study } \\
\text { composed of adults with moderate to } \\
\text { severe depression who had been deemed } \\
\text { non-responsive to at least } 2 \text { other } \\
\text { antidepressants. } 346 \text { patients were } \\
\text { randomized (1:1:1) to esketamine nasal } \\
\text { spray }(56 \mathrm{mg}) \text {, esketamine nasal spray ( } 84 \\
\text { mg), or placebo, all including open-label } \\
\text { oral depressant. The primary endpoint } \\
\text { was comparing baseline Montgomery- } \\
\text { Asberg Depression Rating Scale total } \\
\text { scores to the total score at the end of } 28 \\
\text { days. }\end{array}$ & $\begin{array}{l}\text { There was no statistical significance } \\
\text { achieved between } 84 \mathrm{mg} / \text { antidepressant } \\
\text { and placebo group (least-squares [LS] means } \\
\text { difference [ } 95 \% \mathrm{Cl}]:-3.2[-6.88,0.45] \text {; } \\
2 \text {-sided } \mathrm{P} \text { value }=.088 \text { ). The } 54 \mathrm{mg} / \\
\text { antidepressant group could not be properly } \\
\text { tested. The adverse effects that were most } \\
\text { common in the esketamine/antidepressant } \\
\text { group included headache, vertigo, dizziness, } \\
\text { nausea, and dissociation. }\end{array}$ & $\begin{array}{l}\text { The groups } \\
\text { treated with } \\
\text { esketamine } \\
\text { showed a } \\
\text { difference in } \\
\text { MADRS total } \\
\text { scores. Even } \\
\text { though no } \\
\text { statistical } \\
\text { significance was } \\
\text { found in } \\
\text { esketamine for } \\
\text { TRD, there was } \\
\text { a clinical } \\
\text { significance. } \\
\text { The safety } \\
\text { between all } \\
\text { groups was } \\
\text { deemed similar. }\end{array}$ \\
\hline $\begin{array}{l}\text { Daly et } \\
\text { al. (2018) }\end{array}$ & $\begin{array}{l}\text { Phase 2, double-blind, doubly randomized, } \\
\text { placebo-controlled study in adults who } \\
\text { have been diagnosed with MDD and } \\
\text { history of poor response to } 2 \text { or more } \\
\text { antidepressants. There were four phases. } \\
\text { Phase two consisted of two periods. In } \\
\text { period 1, participants were randomized } \\
\text { (3:1:1:1) into placebo, intranasal } \\
\text { esketamine } 28 \mathrm{mg}, 56 \mathrm{mg} \text {, or } 84 \mathrm{mg} \text { twice } \\
\text { weekly. In period } 2 \text {, moderate to severe } \\
\text { symptom patients were rerandomized. } \\
\text { Outcomes were measured based on } \\
\text { changes from the baseline MADRS total } \\
\text { score. }\end{array}$ & $\begin{array}{l}\text { The change in all three MADRS scores in the } \\
\text { esketamine group compared to the placebo } \\
\text { was statistically significant (esketamine } 28 \\
\mathrm{mg}:-4.2[2.09], \mathrm{P}=.02 ; 56 \mathrm{mg}:-6.3 \text { [2.07], } \mathrm{P} \\
=.001 ; 84 \mathrm{mg}:-9.0 \text { [2.13], } \mathrm{P}<.001) \text {. There } \\
\text { was a significant dose-response } \\
\text { relationship. Only } 5 \% \text { of patients treated } \\
\text { with esketamine experienced adverse } \\
\text { effects. }\end{array}$ & $\begin{array}{l}\text { This clinical } \\
\text { study showed } \\
\text { intranasal } \\
\text { esketamine is } \\
\text { useful in } \\
\text { treating TRD. } \\
\text { Additionally, the } \\
\text { response to } \\
\text { esketamine } \\
\text { persisted for at } \\
\text { least } 2 \text { months } \\
\text { with a lower } \\
\text { dose. }\end{array}$ \\
\hline $\begin{array}{l}\text { Singh et } \\
\text { al. (2016) }\end{array}$ & $\begin{array}{l}\text { A multicenter, randomized, placebo- } \\
\text { controlled trial. Patients diagnosed with } \\
\text { TRD were randomized (1:1:1) to receive } \\
\text { either a placebo or IV infusion of ketamine } \\
\text { over } 40 \text { minutes }(.20 \mathrm{mg} / \mathrm{kg} \text { or } .40 \mathrm{mg} / \mathrm{kg}) \text {. } \\
\text { The endpoint efficacy was determined by } \\
\text { comparing MADRS total scale baseline at } \\
\text { the end of day } 1 \text { and day } 2 \text {. }\end{array}$ & $\begin{array}{l}\text { There was a statistically significant } \\
\text { improvement in patients in both ketamine } \\
\text { groups compared to the placebo group. } \\
\text { (-16.8 ( } 3.00) \text { and }-16.9 \text { ( } 2.61) \text { respectively } \\
\text { for ketamine groups compared with placebo } \\
\text { (-3.8 [2.97]). The common adverse effects } \\
\text { were headache, nausea, and dissociation. } \\
\text { These adverse effects were dose- } \\
\text { dependent. }\end{array}$ & $\begin{array}{l}\text { The study } \\
\text { showed a rapid } \\
\text { and strong } \\
\text { response to the } \\
\text { TRD after the } \\
\text { infusion of } \\
\text { ketamine. }\end{array}$ \\
\hline $\begin{array}{l}\text { Milak et } \\
\text { al. }(2020)\end{array}$ & $\begin{array}{l}\text { Randomized, parallel-group, triple-masked } \\
\text { clinical trial. This trial included } 38 \\
\text { individuals who were diagnosed with } \\
\text { MDD but were not actively suicidal. They } \\
\text { were randomized into a placebo group and } \\
\text { groups receiving } 0.1,0.2,0.3,0.4 \text {, or } 0.5 \\
\text { mg/kg intravenously over } 40 \text { minutes. In } \\
\text { addition to looking at the patients' HDRS, } \\
\text { this clinical study also included looking at } \\
\text { the Glx and GABA levels in } 13 \text {-minute } \\
\text { frames following infusion. }\end{array}$ & $\begin{array}{l}\text { There was an improvement in HDRS score } \\
\text { that positively correlated with blood levels } \\
\text { of ketamine ( } \mathrm{t} 36=2.25 ; \mathrm{P}=.03 \text {; slope } \\
\text { estimate, } 0.070 \text { [ } 95 \% \mathrm{Cl}, 0.007 \text { to } 0.133] \text { ). } \\
\text { Additionally the lower the } \mathrm{Gl} \text { response, } \\
\text { there was a correlation with a better } \\
\text { antidepressant response ( } \mathrm{t} 33=-2.400 ; \mathrm{P}= \\
.02 \text {; slope estimate, }-9.85 \text { [ } 95 \% \mathrm{Cl},-18.2 \text { to } \\
-1.50] \text { ). Adverse effects were seen in some } \\
\text { patients, but it only correlated to blood } \\
\text { ketamine levels in men. }\end{array}$ & $\begin{array}{l}\text { The intravenous } \\
\text { ketamine was } \\
\text { related to a } \\
\text { better } \\
\text { antidepressant } \\
\text { response. The } \\
\text { Glx response } \\
\text { was inversely } \\
\text { correlated with } \\
\text { ketamine dose, } \\
\text { and ketamine } \\
\text { blood levels } \\
\text { were positively } \\
\text { correlated with } \\
\text { antidepressant } \\
\text { activity. }\end{array}$ \\
\hline $\begin{array}{l}\text { Chen et } \\
\text { al. (2019) }\end{array}$ & $\begin{array}{l}\text { A group of patients who had been } \\
\text { diagnosed with TRD was randomized into } \\
\text { three groups where they would receive an } \\
\text { infusion of either } 0.5 \mathrm{mg} / \mathrm{kg} \text { ketamine, } 0.2 \\
\mathrm{mg} / \mathrm{kg} \text { ketamine, or the placebo normal } \\
\text { saline. The efficacy was determined by a } \\
\text { change in the HAMD and MADRS total } \\
\text { score from the baseline. Scores were }\end{array}$ & $\begin{array}{l}\text { There was a significant effect on suicidal } \\
\text { symptoms over the } 14 \text {-day period. The } \\
\text { group that received } 0.5 \mathrm{mg} / \mathrm{kg} \text { infusion } \\
\text { showed more improvement with the suicidal } \\
\text { symptoms compared to the lower dose } \\
\text { group and placebo group when looking at } \\
\text { item } 3 \text { of HAMD and item } 10 \text { of MADRS. }\end{array}$ & $\begin{array}{l}\text { A low-dose } \\
\text { ketamine } \\
\text { infusion was } \\
\text { effective in } \\
\text { reducing } \\
\text { suicidal } \\
\text { symptoms in } \\
\text { patients. }\end{array}$ \\
\hline
\end{tabular}




\begin{tabular}{|c|c|c|c|}
\hline & $\begin{array}{l}\text { taken over a } 14 \text { day period. The anti- } \\
\text { suicidal effects of ketamine were also } \\
\text { observed by looking at certain scores } \\
\text { within the HAMD and MADRS. }\end{array}$ & & \\
\hline $\begin{array}{l}\text { Chen et } \\
\text { al. (2018) }\end{array}$ & $\begin{array}{l}\text { A randomized trial of } 71 \text { participants who } \\
\text { have been diagnosed with TRD. They were } \\
\text { put in three different groups to either } \\
\text { receive } 0.5 \mathrm{mg} / \mathrm{kg} \text { ketamine, } 0.2 \mathrm{mg} / \mathrm{kg} \\
\text { ketamine, or normal saline infusion. At } 40 \\
\text { min, } 240 \text { min, } 3 \text { day, } 7 \text {-day post-infusion, } \\
\text { the MADRS score was taken compared to } \\
\text { baseline and levels of CRP, IL-6, and TNF- } \\
\text { a. }\end{array}$ & $\begin{array}{l}\text { There was a statistically significant decrease } \\
\text { in the MADRS score in the } 0.5 \mathrm{mg} / \mathrm{kg} \text { group } \\
\text { and a decrease in TNF- } \alpha \text { levels post- } \\
\text { infusion. }\end{array}$ & $\begin{array}{l}\text { This study } \\
\text { showed the } \\
\text { utility of } \\
\text { ketamine as an } \\
\text { antidepressant } \\
\text { and a } \\
\text { correlation } \\
\text { between pro- } \\
\text { inflammatory } \\
\text { markers and } \\
\text { TRD. }\end{array}$ \\
\hline $\begin{array}{l}\text { lonescu } \\
\text { et al. } \\
\text { (2018) }\end{array}$ & $\begin{array}{l}\text { A randomized, double-blind study } \\
\text { recruited } 25 \text { patients with severe MDD } \\
\text { with chronic suicidal ideation into groups } \\
\text { to receive saline placebo or six ketamine } \\
\text { infusions ( } 0.5 \mathrm{mg} / \mathrm{kg} \text { over } 45 \text { minutes) over } \\
\text { a three-week period. Efficacy was } \\
\text { determined by comparing a baseline } \\
\text { HDRS score and C-SSRS with scores at } \\
240 \text { min post-infusion and } 3 \text { months } \\
\text { following the three-month period. }\end{array}$ & $\begin{array}{l}\text { There was no statistically significant change } \\
\text { in severity in depression or suicidal ideation } \\
\text { in comparison to the placebo }(p=0.47 \text { and } p \\
=0.32 \text {, respectively). }\end{array}$ & $\begin{array}{l}\text { Repeated doses } \\
\text { of ketamine for } \\
\text { chronic suicidal } \\
\text { ideation did not } \\
\text { show benefit } \\
\text { over the } \\
\text { placebo. }\end{array}$ \\
\hline $\begin{array}{l}\text { Canuso } \\
\text { et al. } \\
\text { (2018) }\end{array}$ & $\begin{array}{l}\text { A double-blind study took } 68 \text { participants } \\
\text { and randomized them into two groups } \\
\text { either receiving } 84 \text { mg of intranasal } \\
\text { esketamine or placebo for } 4 \text { weeks. They } \\
\text { also received standard of care treatment. } \\
\text { The efficacy was judged by a change in the } \\
\text { MADRS score from the baseline score to } \\
\text { the score at } 4 \text { hours, } 24 \text { hours and } 25 \text { days. } \\
\text { Clinical judgment of suicide risk was also } \\
\text { assessed. }\end{array}$ & $\begin{array}{l}\text { There was an improvement in the MADRS } \\
\text { score in patients that received esketamine } \\
\text { compared to the placebo group at the } \\
\text { 4-hour mark (least-square mean } \\
\text { difference }=-5.3, \mathrm{SE}=2.10 ; \text {; effect size }=0.61 \text { ) } \\
\text { and at the } 24 \text {-hour mark (least-square mean } \\
\text { difference=-7.2, SE=2.85; effect size=0.65). } \\
\text { However, at the } 25 \text {-day mark, there was not } \\
\text { a significant difference shown. The clinical } \\
\text { judgment did not show a statistical } \\
\text { difference in suicidal risk scores. The } \\
\text { adverse effects were nausea, dizziness, } \\
\text { dissociation, unpleasant taste, and } \\
\text { headache. }\end{array}$ & $\begin{array}{l}\text { The results } \\
\text { showed } \\
\text { significance in } \\
\text { the use of } \\
\text { intranasal } \\
\text { ketamine in } \\
\text { rapid relief of } \\
\text { depressive and } \\
\text { suicidal } \\
\text { symptoms in } \\
\text { patients at } \\
\text { imminent risk of } \\
\text { suicide when } \\
\text { given in } \\
\text { addition to } \\
\text { standard of care } \\
\text { treatment in } \\
\text { comparison to } \\
\text { the placebo. }\end{array}$ \\
\hline
\end{tabular}




\section{REFERENCES}

1. Sussman M, O'sullivan AK, Shah A, Olfson M, Menzin J. Economic Burden of Treatment-Resistant Depression on the U.S. Health Care System. J Manag care Spec Pharm. 2019;25(7):823-835. doi:10.18553/i mcp.2019.25.7.823

2. Jaffe DH, Rive B, Denee TR. The humanistic and economic burden of treatment-resistant depression in Europe: a cross-sectional study. BMC Psychiatry. 2019;19(1):247. doi:10.1186/s12888-019-2222-4

3. Mion G. History of anaesthesia: The ketamine story - past, present and future. Eur J Anaesthesiol. 2017;34(9):571-575. doi:10.1097/EJA.0000000000000 $\underline{638}$

4. Hashimoto K. Rapid-acting antidepressant ketamine, its metabolites and other candidates: A historical overview and future perspective. Psychiatry Clin Neurosci. 2019;73(10):613-627. doi:10.1111/pcn.1 $\underline{2902}$

5. Esketamine nasal spray (Spravato) for treatmentresistant depression. Med Lett Drugs Ther. 2019;61(1569):54-57.

6. Ivan Ezquerra-Romano I, Lawn W, Krupitsky E, Morgan CJA. Ketamine for the treatment of addiction: Evidence and potential mechanisms. Neuropharmacology. 2018;142:72-82. doi:10.1016/j.ne uropharm.2018.01.017

7. Pribish A, Wood N, Kalava A. A Review of Nonanesthetic Uses of Ketamine. Anesthesiol Res Pract. 2020;2020:5798285. doi:10.1155/2020/5798285

8. Fond G, Loundou A, Rabu C, et al. Ketamine administration in depressive disorders: a systematic review and meta-analysis. Psychopharmacology (Berl). 2014;231(18):3663-3676. doi:10.1007/s00213-014-36 64-5

9. Hartberg J, Garrett-Walcott S, De Gioannis A. Impact of oral ketamine augmentation on hospital admissions in treatment-resistant depression and PTSD: a retrospective study. Psychopharmacology (Berl). 2018;235(2):393-398. doi:10.1007/s00213-01 $\underline{7-4786-3}$

10. Fortress AM, Smith IM, Pang KCH. Ketamine facilitates extinction of avoidance behavior and enhances synaptic plasticity in a rat model of anxiety vulnerability: Implications for the pathophysiology and treatment of anxiety disorders. Neuropharmacology. 2018;137:372-381. doi:10.1016/ j.neuropharm.2018.05.009
11. Glue P, Neehoff S, Sabadel A, et al. Effects of ketamine in patients with treatment-refractory generalized anxiety and social anxiety disorders: Exploratory double-blind psychoactive-controlled replication study. J Psychopharmacol. 2020;34(3):267-272. doi:10.1177/0269881119874457

12. Silote GP, de Oliveira SFS, Ribeiro DE, et al. Ketamine effects on anxiety and fear-related behaviors: Current literature evidence and new findings. Prog Neuropsychopharmacol Biol Psychiatry. 2020;100:109878. doi:10.1016/j.pnpbp.2020.109878

13. Dakwar E, Nunes EV, Hart CL, et al. A Single Ketamine Infusion Combined With MindfulnessBased Behavioral Modification to Treat Cocaine Dependence: A Randomized Clinical Trial. Am J Psychiatry. 2019;176(11):923-930. doi:10.1176/appi.aj p.2019.18101123

14. Jones JL, Mateus CF, Malcolm RJ, Brady KT, Back SE. Efficacy of Ketamine in the Treatment of Substance Use Disorders: A Systematic Review. Front psychiatry. 2018;9:277. doi:10.3389/fpsyt.2018.00277

15. Das RK, Gale G, Walsh K, et al. Ketamine can reduce harmful drinking by pharmacologically rewriting drinking memories. Nat Commun. 2019;10(1):5187. doi:10.1038/s41467-019-13162-w

16. Niciu MJ, Luckenbaugh DA, Ionescu DF, et al. Ketamine's antidepressant efficacy is extended for at least four weeks in subjects with a family history of an alcohol use disorder. Int J Neuropsychopharmacol. 2014;18(1). doi:10.1093/ijnp/pyu039

17. Gaynes BN, Lux L, Gartlehner G, et al. Defining treatment-resistant depression. Depression and anxiety. 2020;37(2):134-145. doi:10.1002/da.22968

18. Reutfors J, Andersson TML, Brenner P, et al. Mortality in treatment-resistant unipolar depression: A register-based cohort study in Sweden. J Affect Disord. 2018;238:674-679. doi:10.1016/j.jad.2018.06.0 $\underline{30}$

19. American Psychiatric Association. Diagnostic and Statistical Manual of Mental Disorders, 5th Edition.; 2013.

20. Verduijn J, Milaneschi Y, Schoevers RA, van Hemert AM, Beekman ATF, Penninx BWJH. Pathophysiology of major depressive disorder: mechanisms involved in etiology are not associated with clinical progression. Transl Psychiatry. 2015;5(9):e649. doi:10.1038/tp.2015.137 
21. Akil H, Gordon J, Hen R, et al. Treatment resistant depression: A multi-scale, systems biology approach. Neurosci Biobehav Rev. 2018;84:272-288. doi:10.1016/ j.neubiorev.2017.08.019

22. Moshe H, Gal R, Barnea-Ygael N, Gulevsky T, Alyagon U, Zangen A. Prelimbic Stimulation Ameliorates Depressive-Like Behaviors and Increases Regional BDNF Expression in a Novel Drug-Resistant Animal Model of Depression. Brain Stimul. 2016;9(2):243-250. doi:10.1016/i.brs.2015.10.009

23. Wilson S, Vaidyanathan U, Miller MB, McGue M, Iacono WG. Premorbid risk factors for major depressive disorder: are they associated with early onset and recurrent course? Dev Psychopathol. 2014;26(4 Pt 2):1477-1493. doi:10.1017/S0954579414 $\underline{001151}$

24. Kautzky A, Dold M, Bartova L, et al. Clinical factors predicting treatment resistant depression: affirmative results from the European multicenter study. Acta Psychiatr Scand. 2019;139(1):78-88. doi:1 0.1111/acps.12959

25. Mullen S. Major depressive disorder in children and adolescents. Ment Heal Clin. 2018;8(6):275-283. $\underline{\mathrm{d}}$ oi:10.9740/mhc.2018.11.275

26. Bennabi D, Charpeaud T, Yrondi A, et al. Clinical guidelines for the management of treatment-resistant depression: French recommendations from experts, the French Association for Biological Psychiatry and Neuropsychopharmacology and the fondation FondaMental. BMC psychiatry. 2019;19(1):262. doi:1 $\underline{0.1186 / \mathrm{s} 12888-019-2237-\mathrm{x}}$

27. Caldarone BJ, Zachariou V, King SL. Rodent models of treatment-resistant depression. Eur J Pharmacol. 2015;753:51-65. doi:10.1016/j.ejphar.201 $\underline{4.10 .063}$

28. Edwards SJ, Hamilton V, Nherera L, Trevor N. Lithium or an atypical antipsychotic drug in the management of treatment-resistant depression: a systematic review and economic evaluation. Health Technol Assess. 2013;17(54):1-190. doi:10.3310/hta17 $\underline{540}$

29. De Berardis D, Fornaro M, Anastasia A, et al. Adjunctive vortioxetine for SSRI-resistant major depressive disorder: a "real-world" chart review study. Rev Bras Psiquiatr. 2020;42(3):317-321. doi:1 0.1590/1516-4446-2019-0690

30. Gáll Z, Farkas S, Albert Á, et al. Effects of Chronic Cannabidiol Treatment in the Rat Chronic Unpredictable Mild Stress Model of Depression. Biomolecules. 2020;10(5). doi:10.3390/biom10050801
31. Zanos P, Gould TD. Mechanisms of ketamine action as an antidepressant. Mol Psychiatry. 2018;23(4):801-811. doi:10.1038/mp.2017.255

32. FDA. FDA approves new nasal spray medication for treatment-resistant depression; available only at a certified doctor's office or clinic.https://www.fda.gov/ news-events/press-announcements/fda-approves-ne w-nasal-spray-medication-treatment-resistant-depre ssion-available-only-certified. Published 2019.

33. Strasburger SE, Bhimani PM, Kaabe JH, et al. What is the mechanism of Ketamine's rapid-onset antidepressant effect? A concise overview of the surprisingly large number of possibilities. J Clin Pharm Ther. 2017;42(2):147-154. doi:10.1111/jcpt.124 $\underline{97}$

34. Williams NR, Schatzberg AF. NMDA antagonist treatment of depression. Curr Opin Neurobiol. 2016;36:112-117. doi:10.1016/j.conb.2015.11.001

35. Williams NR, Heifets BD, Blasey C, et al. Attenuation of Antidepressant Effects of Ketamine by Opioid Receptor Antagonism. Am J Psychiatry. 2018;175(12):1205-1215. doi:10.1176/appi.ajp.2018.1 $\underline{8020138}$

36. Kornhall D, Nielsen EW. Failure of ketamine anesthesia in a patient with lamotrigine overdose. Case reports Crit care. 2014;2014:916360. doi:10.1155/ $\underline{2014 / 916360}$

37. Andrashko V, Novak T, Brunovsky M, Klirova M, Sos P, Horacek J. The Antidepressant Effect of Ketamine Is Dampened by Concomitant Benzodiazepine Medication. Front psychiatry. 2020;11:844. doi:10.3389/fpsyt.2020.00844

38. Hijazi Y, Boulieu R. Contribution of CYP3A4, CYP2B6, and CYP2C9 isoforms to N-demethylation of ketamine in human liver microsomes. Drug Metab Dispos. 2002;30(7):853-858. doi:10.1124/dmd.30.7.85 $\underline{3}$

39. Yanagihara Y, Kariya S, Ohtani M, et al. Involvement of CYP2B6 in n-demethylation of ketamine in human liver microsomes. Drug Metab Dispos. 2001;29(6):887-890.

40. Edwards SR, Mather LE. Tissue uptake of ketamine and norketamine enantiomers in the rat: indirect evidence for extrahepatic metabolic inversion. Life Sci. 2001;69(17):2051-2066. doi:10.101 6/s0024-3205(01)01287-5 
41. Pfenninger EG, Durieux ME, Himmelseher S. Cognitive impairment after small-dose ketamine isomers in comparison to equianalgesic racemic ketamine in human volunteers. Anesthesiology. 2002;96(2):357-366. doi:10.1097/00000542-20020200 0-00022

42. Zielmann S, Kazmaier S, Schnüll S, Weyland A. [S(+)-Ketamine and circulation]. Anaesthesist. 1997;46 Suppl 1:S43-6. doi:10.1007/pl00002464

43. White PF, Ham J, Way WL, Trevor AJ. Pharmacology of ketamine isomers in surgical patients. Anesthesiology. 1980;52(3):231-239. doi:10.1 097/00000542-198003000-00008

44. Kallmünzer B, Volbers B, Karthaus A, Tektas OY, Kornhuber J, Müller HH. Treatment escalation in patients not responding to pharmacotherapy, psychotherapy, and electro-convulsive therapy: experiences from a novel regimen using intravenous S-ketamine as add-on therapy in treatment-resistant depression. J Neural Transm. 2016;123(5):549-552. do i:10.1007/s00702-015-1500-7

45. Bartova L, Vogl SE, Stamenkovic M, et al. Combination of intravenous S-ketamine and oral tranylcypromine in treatment-resistant depression: A report of two cases. Eur Neuropsychopharmacol J Eur Coll Neuropsychopharmacol. 2015;25(11):2183-2184. $\underline{\mathrm{d}}$ oi:10.1016/j.euroneuro.2015.07.021

46. Segmiller F, Rüther T, Linhardt A, et al. Repeated S-ketamine infusions in therapy resistant depression: a case series. J Clin Pharmacol. 2013;53(9):996-998. do $\mathrm{i}: 10.1002 / j \mathrm{cph} .122$

47. Zhang JC, Li SX, Hashimoto K. R (-)-ketamine shows greater potency and longer lasting antidepressant effects than S (+)-ketamine. Pharmacol Biochem Behav. 2014;116:137-141. doi:10.1 016/i.pbb.2013.11.033

48. Andrade C. Ketamine for Depression, 3: Does Chirality Matter? J Clin Psychiatry.

2017;78(6):e674-e677. doi:10.4088/JCP.17f11681

49. Fedgchin M, Trivedi M, Daly EJ, et al. Efficacy and Safety of Fixed-Dose Esketamine Nasal Spray Combined With a New Oral Antidepressant in Treatment-Resistant Depression: Results of a Randomized, Double-Blind, Active-Controlled Study (TRANSFORM-1). Int J Neuropsychopharmacol. 2019;22(10):616-630. doi:10.1093/ijnp/pyz039

50. Daly EJ, Singh JB, Fedgchin M, et al. Efficacy and Safety of Intranasal Esketamine Adjunctive to Oral Antidepressant Therapy in Treatment-Resistant Depression: A Randomized Clinical Trial. JAMA psychiatry. 2018;75(2):139-148. doi:10.1001/jamapsyc hiatry.2017.3739
51. Singh JB, Fedgchin M, Daly E, et al. Intravenous Esketamine in Adult Treatment-Resistant Depression: A Double-Blind, Double-Randomization, Placebo-Controlled Study. Biol Psychiatry. 2016;80(6):424-431. doi:10.1016/j.biopsych.2015.10.0 18

52. Milak MS, Rashid R, Dong Z, et al. Assessment of Relationship of Ketamine Dose With Magnetic Resonance Spectroscopy of Glx and GABA Responses in Adults With Major Depression: A Randomized Clinical Trial. JAMA Netw Open. 2020;3(8):e2013211. doi:10.1001/jamanetworkopen.2020.13211

53. Chen MH, Lin WC, Wu HJ, et al. Antisuicidal effect, BDNF Val66Met polymorphism, and low-dose ketamine infusion: Reanalysis of adjunctive ketamine study of Taiwanese patients with treatment-resistant depression (AKSTP-TRD). J Affect Disord. 2019;251:162-169. doi:10.1016/i.jad.2019.03.075

54. Chen MH, Li CT, Lin WC, et al. Rapid inflammation modulation and antidepressant efficacy of a low-dose ketamine infusion in treatmentresistant depression: A randomized, double-blind control study. Psychiatry Res. 2018;269:207-211. doi:1 0.1016/j.psychres.2018.08.078

55. Ionescu DF, Bentley KH, Eikermann M, et al. Repeat-dose ketamine augmentation for treatmentresistant depression with chronic suicidal ideation: A randomized, double blind, placebo controlled trial. Psychiatry Res. 2019;243:516-524. doi:10.1016/j.jad.2 018.09.037

56. Canuso CM, Singh JB, Fedgchin M, et al. Efficacy and Safety of Intranasal Esketamine for the Rapid Reduction of Symptoms of Depression and Suicidality in Patients at Imminent Risk for Suicide: Results of a Double-Blind, Randomized, PlaceboControlled Study. Am J Psychiatry. 2018;175(7):620-630. doi:10.1176/appi.ajp.2018.1706 $\underline{0720}$

57. Chang L, Zhang K, Pu Y, et al. Comparison of antidepressant and side effects in mice after intranasal administration of (R,S)-ketamine, (R)ketamine, and (S)-ketamine. Pharmacol Biochem Behav. 2019;181:53-59. doi:10.1016/i.pbb.2019.04.008

58. Muller J, Pentyala S, Dilger J, Pentyala S. Ketamine enantiomers in the rapid and sustained antidepressant effects. Ther Adv Psychopharmacol. 2016;6(3):185-192. doi:10.1177/2045125316631267

59. Correia-Melo FS, Leal GC, Carvalho MS, et al. Comparative study of esketamine and racemic ketamine in treatment-resistant depression: Protocol for a non-inferiority clinical trial. Medicine (Baltimore). 2018;97(38):e12414. doi:10.1097/MD.000 0000000012414 
60. Gautam CS, Mahajan SS, Sharma J, Singh H, Singh J. Repurposing Potential of Ketamine: Opportunities and Challenges. Indian J Psychol Med. 2020;42(1):22-29. doi:10.4103/IJPSYM.IJPSYM 2281 $\underline{9}$

61. Carreno FR, Lodge DJ, Frazer A. Ketamine: Leading us into the future for development of antidepressants. Behav Brain Res. 2020;383:112532. d oi:10.1016/j.bbr.2020.112532
62. Smith-Apeldoorn SY, Veraart JKE, Kamphuis J, et al. Oral esketamine for treatment-resistant depression: rationale and design of a randomized controlled trial. BMC Psychiatry. 2019;19(1):375. doi:1 0.1186/s12888-019-2359-1

63. Pérez-Esparza R, Kobayashi-Romero LF, GarcíaMendoza AM, Lamas-Aguilar RM, FonsecaPerezamador A. Promises and concerns regarding the use of ketamine and esketamine in the treatment of depression. Acta Psychiatr Scand. 2019;140(2):182-183. doi:10.1111/acps.13063 